\title{
Prevalence of comorbidities in children with attention deficit/hyperactivity disorder: Measured and systematic review of care health studies
}

\author{
Denise Medici, ${ }^{1,2 *}$, María M. Suarez-Varela ${ }^{2,3}$, and Rubén Pérez-Elvira ${ }^{4}$ \\ ${ }^{1}$ Department of Neuropsychology, Hospital Vithas Nisa 9 de Octubre, Valencia, Spain; ${ }^{2}$ Department of Preventive Medicine, University of Valencia, \\ Valencia, Spain; ${ }^{3}$ Department of Biomedical Research Consortium for Epidemiology and Public Health (CIBERESP), Valencia, Spain; ${ }^{4}$ NEPSA \\ Neurological Rehabilitation, Salamanca, Spain
}

\begin{abstract}
Background and objectives: Children and adolescents with a diagnosis of attention deficit hyperactivity disorder demonstrate a developmental delay in emotional and social functions, sleep difficulties, enuresis, and/or paroxysms in electroencephalographic measurements. The purpose of the study is to know if there is an association between comorbidities and $A D H D$. The second objective was to compare the results with previous studies in different countries. Material and methods: Retrospective analysis of a clinical database (CDB) was conducted identifying 1049 Spanish children and adolescents diagnosed with ADHD according to DSM-IV (Diagnostic and Statistical Manual of Mental Disorders) in the Department of Pediatrics of the Hospital Universitario Dr. Peset. Results: In the 297 CDB aged 6 - 16 years children included, the comorbidities were statistically significant. This medical conditions in Spanish children with ADHD coexist outside of Spain and are statistically significant in all aspects analyzed except in anxiety, Asperger's syndrome and enuresis. Conclusions: Our results support the association between comorbidities and ADHD. It is important for professionals to make sure that they identify different comorbidities during the diagnostic process as during the clinical follow-up. The article is recommended to teachers, therapists and health professionals, for adopting a proactive and intermodal team approach in the detection and treatment of comorbidities in children and youth.
\end{abstract}

Key words: Attention deficit hyperactivity disorder. Comorbidities. Detection. Diagnosis.

\section{Prevalencia de comorbilidades en niños con trastorno por déficit de atención/ hiperactividad: revisión medida y sistemática de estudios de salud asistencial}

\section{Resumen}

Antecedentes y objetivos: Los niños y adolescentes con diagnóstico de Trastorno por Déficit de Atención/Hiperactividad (TDAH) presentan un retraso en el desarrollo de las funciones sociales y emocionales, dificultades para dormir, enuresis y/o paroxismos en las mediciones electroencefalográficas (EEG). El propósito del estudio es saber si existe una asociación entre las comorbilidades y el TDAH. El segundo objetivo fue comparar los resultados con estudios previos en diferentes

\footnotetext{
Correspondence:

*Denise Medici

Valle de la Ballestera, 59

Date of reception: 15-11-2019

C.P. 46015, Valencia, España

E-mail: denise_medici@yahoo.es

Available online: 05-08-2020 Rev Mex Neuroci. 2020;21(4):143-149 www.revmexneurociencia.com

1665-5044/ @ 2020. Academia Mexicana de Neurología A.C. Published by Permanyer. This is an open access article under the CC BY-NC-ND license (http://creativecommons.org/licenses/by-nc-nd/4.0/).
} 
países. Método: Se realizó un análisis retrospectivo de una base de datos de historias clínicas (CDB) que identificó a 1049 niños y adolescentes españoles diagnosticados con TDAH de acuerdo con el DSM-IV (Manual diagnóstico y estadístico de trastornos mentales) en el Departamento de Pediatría del Hospital Universitario Dr. Peset. Resultados: En las 297 CDB de niños con edades entre los 6 a 16 años, las comorbilidades fueron estadísticamente significativas. Estas condiciones médicas en niños españoles con TDAH coexisten fuera de España y han sido estadísticamente significativos en todos los aspectos analizados, excepto en ansiedad, síndrome de Asperger y enuresis. Conclusiones: Nuestros resultados apoyan la asociación entre comorbilidades y TDAH. Es importante que los profesionales se aseguren de identificar las diferentes comorbilidades durante el proceso de diagnóstico y durante el seguimiento clínico. El artículo se recomienda a maestros, terapeutas y profesionales de la salud para que adopten un enfoque de equipo proactivo e intermodal en la detección y tratamiento de comorbilidades en niños y jóvenes.

Palabras clave: Trastorno por déficit de atención/hiperactividad. TDAH. Comorbilidades. Detección. Diagnóstico.

\section{Introduction}

Attention deficit hyperactivity disorder (ADHD) is the most commonly diagnosed neurodevelopmental disorder of childhood, and it is associated with social and academic difficulties and psychiatric comorbidities such as depression, anxiety, low self-esteem, and pervasive across settings can cause problems in the daily activities of a child as well as later in their adult life 1 . In addition, studies detected difficulties in behavioral regulation and emotional stability in children younger than 2 years of age who were later diagnosed diagnosis with $A D H D^{2}$. ADHD during childhood is one of the most common causes of school failure and social problems. It is a disorder that can persist and manifest in adulthood in more than $60 \%$ of cases. Several studies have found that the quality of life in adolescents and in adults who were diagnosed with ADHD during their childhood is clearly related to the severity of comorbidities symptoms ${ }^{3}$. In studies with adults who have a residual form of this disorder, the research has found a higher frequency of behavioral abnormalities in labor activities and in family relationships, substance abuse, accidents, and crime ${ }^{4}$. Depression during childhood and adolescence also predicts negative outcomes in adulthood such as stressful life events, low social support, and low satisfaction with life ${ }^{5}$. Maternal depression and concurrent symptoms at 4-6 years of age predict which children with ADHD are at greatest risk for depression and/or suicidality as adolescents ${ }^{6}$. A diagnosis of both ADHD and depression is associated with the most significant deficiencies for either disorder than one alone. For example, young people with ADHD and depression have an increased risk of developing bipolar disorder and oppositional defiant disorder, and require much more intensive interventions compared to young people with ADHD but without depression ${ }^{5}$. Interventions for both diagnoses also report more psychosocial and family problems as well as higher levels of stress $^{7,8}$. Despite the impact of ADHD and depressive symptoms in young people, few studies have examined the underlying mechanisms which contribute to the emergence of these symptoms ${ }^{9}$. One promising mechanism is emotion regulation (ER), as the deficit in the ability of ER has been associated with young children with ADHD and with depressive symptoms. This point is primarily relevant for young people with ADHD symptoms as it emphasizes the role of effort in control - the deliberate modulation of emotional states, emotional regulation, and subsequent behaviors, which involve the ability to focus deliberately, divert attention, hyperactivity, and inhibit or activate an appropriate behavior ${ }^{10-12}$. Several studies suggest that young people with ADHD demonstrate an inability to continue a task when frustrated or they have an inability to seek help from their parents. In extreme levels, when they are solving more limited problems, they focus more on negative aspects of a task compared to healthy controls. Young people with ADHD also have difficulties identifying and processing negative emotions and high-stress exposure between childhood and young adulthood is strongly intertwined with a persistent course of ADHD and with comorbid problems taking the form of severe and persistent emotion dysregulation (irritability, extreme reactivity, and frustration) or elevated and increasing irritability, anxiety, and depression ${ }^{13,14}$. Longitudinal research has shown that the ADHD diagnosis persists into adulthood, participants manifest higher levels of impulsive emotions (defined by symptoms such as low tolerance to frustration, impatience, and irritability) compared to those who do not have ADHD as an adult. This situation contributes to deficits in family, peer, financial, and labor relationships ${ }^{15}$. When comparing subtypes, children with inattentive ADHD have a higher rate in eating disorders, anxiety, and depression than in those with hyperactive and/or combined ADHD. In this both hyperactive and combined ADHD, children often have social problems, as they take things that do not belong to them, 
do not wait their turn, and act without considering before the feelings of others. Children with ADHD inattentive type, rather, tend to be socially isolated, self-absorbed, and most likely have an introverted behavior ${ }^{16}$ (Diamond, 2005). ADHD without hyperactivity and ADHD with hyperactivity are two different disorders with different cognitive and behavioral profiles, different patterns of comorbidities, different responses to medication, and different underlying neurobiology ${ }^{16}$ characteristics that become chronic and progressively worse (i.e., findings support the diagnosis of ADHD in younger children by demonstrating that the symptoms and associated impairment are likely to persist well into elementary school) ${ }^{17}$. It is unclear whether the features of anxiety and ADHD are possible to identify very early of age; for example, in one child, his emotional deregulation at 18 months of age was associated with symptoms of anxiety and ADHD at 3 years of age. The study could not confirm if the emotional deregulation at 18 months predicts the cooccurrence of anxiety and ADHD symptoms. This implies that the identification risk at 18 months is a clinical challenge. By identifying early, there is a risk of over-identification and treatment of preschool children who are not going to develop ADHD or anxiety in their immediate future ${ }^{18}$. However, longitudinal studies in school-age children found continuity of symptoms for anxiety and ADHD ${ }^{19,20}$. In children with ADHD with an anxiety disorder have more than $50 \%$ of them also oppositional defiant disorder or conduct disorder ${ }^{21}$.

The relationship between ADHD and sleep disorders is unclear. According to a categorical approach, specific sleep disorders are a common comorbidity in children with ADHD. Those with ADHD more often display hypopnea and/or apnea, movements in peripheral limbs during sleep, insomnia, and narcolepsy which could result in significant functional impairments that affect mood, attention, behavior, and ultimately school/work performance and quality of life ${ }^{22}$. Polysomnography shows an increased latency in sleep onset of families ADHD children report less maintenance and duration of sleep, resistance by the child at bedtime, difficulties in sleep onset, difficult in nocturnal breathing, enuresis, nocturnal awakenings, and difficulty in waking up in the morning and daytime sleepiness ${ }^{23}$. In another multicenter cross-sectional study in 12 Spanish hospitals, neurologists reported that sleep disorder affects less than a quarter of patients $(24.5 \%)$ and up to $23 \%$ stated that the prevalence was $<10 \%$, while between $58 \%$ and $92 \%$ of parents of patients attending consultations in pediatric neurology report that their children have some aspect disturbed in the sleep. Although most neurologists appreciate the importance of diagnosis and treatment of sleep disorders in children with neurological disorders, it is often underestimated and therefore essential to include in ADHD evaluations as proper and early treatment would improve symptoms and the quality of life in patients and families ${ }^{24}$.

Moreover, many children with ADHD develop epilepsy. In one study of 23 patients with epilepsy, 19 of them had ADHD symptoms preceding the onset of seizures ${ }^{25}$. An epidemiological study showed that the risk of epilepsy is 2.5 times higher in children who have already developed symptoms of $A D H D^{26}$. With regard to abnormal electroencephalographic (EEG) recordings outside epilepsy, a recent study found abnormal EEG readings in 19 of 50 children diagnosed with ADHD. The most abnormal results were in focal and generalized paroxysms of sharp waves in phase opposition and slow waves. The most frequent location of EEG abnormalities was in the temporal lobe $(45 \%)$, although there were focal paroxysms in other lobes; $28 \%$ in the right temporal region, $17 \%$ in the left temporal region, and $22 \%$ in the left frontal lobe, followed by $11 \%$ in the left parietal region ${ }^{27}$.

In children's ADHD diagnosis, enuresis is a relatively new clinical aspect and is part of our ongoing effort to better understand comorbidities. Children with ADHD are more likely than their peers without ADHD to develop enuresis with a similar trend for encopresis and comorbid enuresis implying an immaturity in the developing nervous system of children who have this combination of problems ${ }^{28}$. Children with primary nocturnal enuresis (PNE) show a significant reduction in activity in the left posterior cerebellum compared to controls without $\mathrm{PNE}^{29}$. Similarly, functional magnetic resonance imaging (fMRI) demonstrated low activation in the right prefrontal cortex and increased activity in the left hemisphere during inhibition of motor response compared to controls without PNA, indicating abnormal network brain areas during response inhibition in children with $\mathrm{PNE}^{30}$.

Therefore, this study aims to characterize the diagnostic complexity of children and adolescents who receive a diagnosis of ADHD. These findings could be helpful to develop guidelines that reflect the needs of children with ADHD. We treat a review of the comorbidities in itself complex in the diagnosis of ADHD.

\section{Methods}

\section{Participants}

Retrospective analysis of a clinical database (CDB) was conducted identifying 1049 Spanish children and 
Table 1. Total excluded and included

$$
\begin{aligned}
& 226 \text { participants born since } 1990 \text { and } 1998 \\
& 379 \text { participants without an interdisciplinary diagnosis } \\
& 14 \text { participants had ADS } \\
& 47 \text { participants had a neurological disease diagnosed as } \\
& \text { epilepsy, brain traumatic } \\
& 9 \text { participants had a genetic syndrome diagnosed as deletions } \\
& 26 \text { participants coming from national or international adoptions } \\
& \text { or born in Spain of foreign parents } \\
& 39 \text { participants had not neurophysiological studies (EEG, qEEG, } \\
& \text { and ERPs) }
\end{aligned}
$$

12 participants without approach less medical data

Total included

297 participants met the clinical criteria

ADS: autism spectrum disorder; EEG: electroencephalographic; qEEG: quantitative EEG; ERPs: event-related potentials.

adolescents diagnosed with ADHD according to the DSM-IV (Diagnostic and Statistical Manual of Mental Disorders) in the Department of Pediatrics of the Hospital Universitario Dr. Peset. The comorbidities were diagnosed in the corresponding medical service (Pediatrics, Mental Health, Neurology). Personal and clinical data of patients were reviewed to determine those who met the clinical criteria previously established and described below. After eliminating patients who did not meet for the above, 297 CDB aged 6-16 years of children (79 females and 218 males; mean age, 09.10 years) diagnosed with ADHD were used for this study.

\section{Inclusion criteria}

- Patients diagnosed with ADHD born in Spain from January 1999 to December 2009.

- Patients diagnosed with ADHD with intelligence quotient (IQ) of 80 or higher with Spanish parents.

- Patients diagnosed with ADHD who attended medical appointments.

\section{Exclusion criteria}

- Patients diagnosed with ADHD born and raised from January 1999 to December 2009 in Spain with IQ below 80.

- Patients aged in or outside the range 6-15 years and 11 months adopted or born and raised in Spain of foreign parents
- Patients diagnosed with ADHD who not attended medical appointments.

- Patients diagnosed with ADHD who later acquired brain injury, surgery, and/or neurological diseases such as traumatic brain injury, epilepsy, and/or Gilles de la Tourette Syndrome (Table 1).

In the following table are described by the participants: Medical data related to the child were recorded in a confidential database for exclusive use of the project. Data about diagnosis, treatments, personal circumstances, and about clinical evolution were collected according to the law $15 / 99$ on protection of personal data.

\section{Statistical analysis}

First, descriptive statistics as comorbidity prevalence of the different pathologies studies and their confidence interval $95 \%$ were calculated. The relationships between the categorical variables the prevalence of ADHD child's comorbidity with the ADHD child's without comorbidity were analyzed using the Chi-square test $(p<0.05)$ by each comorbidity studied. Finally, a comparison of each comorbidity prevalence identify was also compared through the review of outside studies from other countries; it was analyzed using the Chi-square test $(p<0.05)$. Statistical analyses were conducted using IBM SPSS Statistics 25.

\section{Results}

Many children diagnosed with ADHD have comorbidities. In Spain, children and adolescents diagnosed with ADHD, the current study found that all potential comorbid conditions were statistically significant in the aspects analyzed ( $p \leq 0.001)$ (Table 2$)$. When examining outside studies, results on the presence or absence of conditions that coexist in children diagnosed with ADHD outside of Spain are statistically significant in all aspects analyzed ( $p \leq 0.001)$, except in anxiety, and in Asperger's disease ${ }^{31}$ and in female and male Enuresis ${ }^{32}$ (Table 2a).

\section{Discussion}

In this study in ADHD, $25 \%$ of patients showed social problems, $28 \%$ depression and/or anxiety, and 19\% had difficulties in the maintenance of nighttime sleep. The results were associated with those obtained by Hoza $^{12}$, Mellon ${ }^{28}$, and Sheerman ${ }^{32}$ in United States of America, by Chou in China ${ }^{33}$, by Fonseca in Brazil ${ }^{34}$, 
Table 2. Prevalence of comorbidities in children with attention deficit hyperactivity disorder for the sample $(n=297)$

\begin{tabular}{|c|c|c|c|c|}
\hline Variable & Frequency (n) & Prevalence (\%) & Prevalence $(95 \%$ CI) & Chi-square test (p) \\
\hline Peer/dyadic relationship difficulties & 74 & 25.00 & $20.18-30.31$ & $\leq 0.001$ \\
\hline Depression/anxiety & 83 & 28.00 & 23.62-34.18 & $\leq 0.001$ \\
\hline Anxiety & 41 & 14.00 & $10.48-18.74$ & \\
\hline Sleep disorders & 56 & 18.90 & $15.87-25.31$ & $\leq 0.001$ \\
\hline Insomnia for lack of limits on family & 7 & 2.35 & $1.25-5.44$ & $\leq 0.001$ \\
\hline Nocturnal enuresis & 15 & 5.10 & $2.95-8.36$ & $\leq 0.001$ \\
\hline Snorer & 3 & 1.01 & $0.26-3.17$ & $\leq 0.001$ \\
\hline Nighttime awakenings & 11 & 3.70 & $1.95-6.71$ & $\leq 0.001$ \\
\hline Delay sleep onset syndrome & 3 & 1.01 & $0.26-3.17$ & $\leq 0.001$ \\
\hline Restless leg syndrome & 3 & 1.01 & $0.26-3.17$ & $\leq 0.001$ \\
\hline Bruxism & 3 & 1.01 & $0.26-3.17$ & $\leq 0.001$ \\
\hline Catathrenia (night whimper) & 4 & 1.70 & $0.43-3.64$ & $\leq 0.001$ \\
\hline Night terrors & 2 & 0.70 & $0.11-2.67$ & $\leq 0.001$ \\
\hline Somniloquy & 5 & 1.70 & $0.62-4.10$ & $\leq 0.001$ \\
\hline Epilepsy (EEG) & 72 & 24.35 & $19.69-29.79$ & $\leq 0.001$ \\
\hline Primary nocturnal enuresis & 10 & 3.37 & $1.72-6.29$ & \\
\hline Female & 2 & 0.67 & $0.11-2.67$ & \\
\hline Male & 8 & 2.70 & $1.25-5.44$ & 0.055 \\
\hline
\end{tabular}

ANOVA test: $p<0.01$. RF: relative frequency; \%: proportion; 95\% Cl: Confidence Interval 95\%; p: Fisher values; EEG: encephalogram.

Table 2a. Comorbidities in children with attention deficit hyperactivity disorder according to previous studies

\begin{tabular}{|l|c|c|c|c|l|}
\hline Variable & $\begin{array}{c}\text { Frequency } \\
(\mathbf{n})\end{array}$ & $\begin{array}{c}\text { Prevalence } \\
(\mathbf{\%})\end{array}$ & $\begin{array}{c}\text { Prevalence } \\
(\mathbf{9 5} \% \mathbf{C l})\end{array}$ & $\begin{array}{c}\text { Chi-square } \\
\text { test (p) }\end{array}$ & Previous studies \\
\hline Peer/dyadic relationship difficulties & 92 & 56.00 & $47.83-63.41$ & $\leq 0.001$ & Hoza, 2005 \\
\hline Depression & 10 & 6.70 & $3.59-12.82$ & 0.029 & Bauermeister, 2007 \\
\hline Depression & 68 & 21.30 & $17.03-23.30$ & 0.020 & Silva, 2015 \\
\hline Anxiety & 34 & 23.77 & $17.23-31.75$ & 0.012 & Bauermeister, 2007 \\
\hline Anxiety & 169 & 52.60 & $47.34-58.54$ & $\leq 0.001$ & Silva, 2015 \\
\hline Anxiety & 12 & 11.90 & $6.55-20.20$ & 0.665 & Ogrim, 2012 \\
\hline Asperger syndrome (symptoms) & 5 & 4.95 & $1.83-11.71$ & 0.148 & Ogrim, 2012 \\
\hline Sleep disorders & 45 & 31.46 & $24.10-39.84$ & 0.003 & Bauermeister, 2007 \\
\hline Epilepsy 6-18 years old (EEG) & 2843 & 15.63 & $15.10-16.17$ & $\leq 0.001$ & Chou, 2013 \\
\hline Epilepsy 8-11 years old (EEG) & 3 & 10.00 & $2.61-27.67$ & 0.095 & Fonseca, 2008 \\
\hline Primary nocturnal enuresis & 100 & 9.00 & $7.25-10.63$ & 0.044 & Shreeram, 2009 \\
\hline Female & 32 & 2.51 & $1.95-4.00$ & 0.198 & \\
\hline Male & 68 & 6.21 & $4.70-7.56$ & 0.216 & $\leq 0.001$ \\
\hline Primary nocturnal enuresis & 35 & 12.10 & $6.99-13.45$ & Mellon, 2013 \\
\hline Primary nocturnal enuresis & 165 & 17.60 & $15.02-19.94$ & 0.010 & Joinson, 2007 \\
\hline
\end{tabular}

ANOVA test: $p<0.01(11,20,8,33,34,28,35) ; p \leq 0.05(31,32)$. RF: relative frequency; \%: proportion; $95 \%$ Cl: Confidence Interval 95\%; p: Fisher values; EEG: electroencepham. 
by Joinson in United Kingdom ${ }^{35}$, by Silva in Australia ${ }^{9}$, and by Bauermeister in Puerto Rico ${ }^{20}$.

Children with ADHD often have conflicts with adults and peers, and suffer from unpopularity, rejection by peers, and a lack of friendships, in part as a consequence of their ADHD symptoms. In summary, social relations are also one of the biggest problems in children with ADHD. Parents, teachers, and their own colleagues systematically report that those with $A D H D$ can be aggressive, intrusive, disruptive, manipulative, and less able to communicate and socialize effectively ${ }^{11,13,36}$. Some studies reported little difference and related problems between genders ${ }^{20}$.

Parents with ADHD children compared with normative data reported more problems in terms of emotional-behavioral role function, behavior, mental health, and self-esteem. Children with multiple comorbidity disorders have poorer psychosocial health-related quality of life across a range of domains compared with children with none and one comorbid disorder ${ }^{4}$. In addition, compared to children who have no comorbidities, psychosocial health-related quality of life was significantly lower in children with comorbid oppositional defiant disorder or conduct disorder, but not in children with a comorbid learning disorder ${ }^{4}$. In summary, social relations are one of the biggest problems in children with ADHD.

Sleep disorders may also induce symptoms of ADHD and are believed to be the result of excessive daytime sleepiness. However, it may be difficult for the clinical professional to recognize differences between the comorbidity from one sleep disorder to similar symptoms in $\mathrm{ADHD}^{37,38}$. We found abnormal results in $24.35 \%$ of patients; therefore, the EEG is a valid study in the valuation process for test underlying or comorbid epilepsy in children with ADHD. Epilepsy and ADHD can affect social, educational, and emotional life. The association between ADHD and epilepsy is of great interest in many studies published recently because children with epilepsy have a significant risk in presenting ADHD, and often display deficits in the performance of working memory $26,33,39$. Studies have detected significant similarities between epilepsy and ADHD in males (citation). ADHD with or without epilepsy may share a common abnormal and underlying neurobiological cause ${ }^{40}$.

In our study, the PNE in children with ADHD was in $5.05 \%$, we consider the increase of psychological problems reported by parents of children with enuresis compared to those children without enuresis, and the possible pathogenic etiological between ADHD and incontinence according to neurophysiological and neuroimaging results ${ }^{30}$. However, enuresis is difficult to treat and show lower compliance. Given results in the treatment in incontinence are appreciated in the relevant clinical data regarding ADHD and enuresis, this appears to be a main comorbid condition that should be evaluated and specifically address in ADHD children ${ }^{40}$.

\section{Conclusions}

The current study carried out a broad and comprehensive characterization of comorbidities in children and adolescents with ADHD in an effort to promote appropriate clinical decision making and reduced confusion. Detection and resolution of depressive symptoms, anxious symptoms, and/or difficulties in sleep in those diagnosed with ADHD may reduce emotional risk and morning fatigue. It is very important to detect these symptoms to decrease social and cognitive consequences. Finally, using EEG in this population provides greater assessment and diagnosis of complex developmental disorders such as ADHD.

\section{Study limitations}

First, we recruited data about ADHD comorbidities from different medical specialties departments at the hospital. Our findings should be interpreted in light of limitations. Accordingly, we were unable to stratify symptoms according to high- and low-comorbidity. Second, we were not able to test whether comorbidities are unique to children with ADHD or are also observed in other disorders such as depression and learning delay. Future studies are needed about the relationship between comorbidities and ADHD.

\section{Acknowledgments}

The authors would like to thank the approbation of the study to the Ethics Committee for Clinical Research of the Hospital Universitario Dr. Peset of Valencia, Spain in 2015. It was conducted with not supported in keeping with the Declaration of Helsinki (World Medical Association, 2013, October) Ethics Committee: 10/061 and $11 / 083$.

\section{Funding}

No funding was provided for this project. 


\section{Conflicts of interest}

The authors declare that they have no conflicts of interest.

\section{Ethical disclosures}

Protection of human and animal subjects. The authors declare that no experiments were performed on humans or animals for this study.

Confidentiality of data. The authors declare that no patient data appear in this article.

Right to privacy and informed consent. The authors declare that no patient data appear in this article.

\section{References}

1. Harpin VA. The effect of ADHD on the life of an individual, their family, and community from preschool to adult life. Arch Dis Child. 2005;90 Suppl 1:i2-7.

2. Magallón S, Crespo-Eguílaz N, Ecay M, Poch-Olivé ML, Narbona J. Estilo comportamental al inicio del segundo año de vida: estudio retrospectivo en escolares afectados de trastorno por déficit de atención e hiperactividad. An Pediatr. 2009;70:562-9.

3. Klassen AF, Miller A, Fine S. Health-related quality of life in children and adolescents who have a diagnosis of attention-deficit/hyperactivity disorder. Pediatrics. 2004;114:e541-7.

4. McGough JJ, Smalley SL, McCracken JT, Yang M, Del'Homme M Lynn DE, et al. Psychiatric comorbidity in adult attention deficit hyperactivity disorder: findings from multiplex families. Am J Psychiatry. 2005; 162:1621-7.

5. Biederman J, Ball SW, Monuteaux MC, Mick E, Spencer TJ, MCCREARY M, et al. New insights into the comorbidity between ADHD and major depression in adolescent and young adult females. J Am Acad Child Adolesc Psychiatry. 2008;47:426-34.

6. Chronis-Tuscano A, Molina BS, Pelham WE, Applegate B, Dahlke A, Overmyer $\mathrm{M}$, et al. Very early predictors of adolescent depression and suicide attempts in children with attention-deficit/hyperactivity disorder. Arch Gen Psychiatry. 2010;67:1044-51.

7. Bussing R, Mason DM, Bell L, Porter P, Garvan C. Adolescent outcomes of childhood attention-deficit/hyperactivity disorder in a diverse community sample. J Am Acad Child Adolesc Psychiatry. 2010;49:595-605.

8. Silva D, Houghton S, Hagemann E, Bower C. Comorbidities of attention deficit hyperactivity disorder: pregnancy risk factors and parent mental health. Community Ment Health J. 2015;51:738-45.

9. Martel MM, Nigg JT. Child ADHD and personality/temperament traits of reactive an effortful control resiliency and emotionality. J Child Psychol Psychiatry. 2009;46:1437-44

10. Seymour KE, Chronis-Tuscano A, Iwamoto DK, Kurdziel G, Macpherson L. Emotion regulation mediates the association between ADHD and depressive symptoms in a community sample of youth. J Abnorm Child Psychol. 2014;42:611-21.

11. Landis TD, Garcia AM, Hart KC, Graziano PA. Differentiating symptoms of $A D H D$ in preschoolers: the role of emotion regulation and executive function. J Atten Disord. 2020; Jan 6:1087054719896858.

12. Hoza B, Mrug S, Gerdes AC, Hinshaw SP, Bukowski WM, Gold JA, et al. What aspects of peer relationships are impaired in children with attention-deficit/hyperactivity disorder? J Consult Clin Psychol. 2005;73:411-23.

13. Hartman CA, Rommelse $N$, van der Klugt $C L$, Wanders RB, Timmerman ME. Stress exposure and the course of ADHD from childhood to young adulthood: comorbid severe emotion dysregulation or mood and anxiety problems. J Clin Med. 2019;8:E1824.

14. Barkley RA, Fischer M. The unique contribution of emotional impulsiveness to impairment in major life activities in hyperactive children as adults. J Am Acad Child Adolesc Psychiatry. 2010;49:503-13.

15. Diamond A. Attention-deficit disorder (attention-deficit/hyperactivity disorder without hyperactivity): a neurobiologically and behaviorally distinct disorder from attention-deficit/hyperactivity disorder (with hyperactivity). Dev Psychopathol. 2005;17:807-25
16. Lahey BB, Pelham WE, Loney J, Kipp H, Ehrhardt A, Lee SS, et al. Three-year predictive validity of DSM-IV attention deficit hyperactivity disorder in children diagnosed at 4-6 years of age. Am J Psychiatry. 2004:161:2014-20.

17. Overgaard KR, Aase H, Torgersen S, Reichborn-Kjennerud T, Oerbeck B, Myhre A, et al. Continuity in features of anxiety and attention deficit/ hyperactivity disorder in young preschool children. Eur Child Adolesc Psychiatry. 2014;23:743-52.

18. Larsson H, Dilshad R, Lichtenstein P, Barker ED. Developmental trajectories of DSM-IV symptoms of attention-deficit/hyperactivity disorder: genetic effects, family risk and associated psychopathology. J Child Psychol Psychiatry. 2011;52:954-63.

19. Bauermeister JJ, Bird HR, Shrout PE, Chavez L, Ramírez R, Canino G. Short-term persistence of DSM-IV ADHD diagnoses: influence of context, age, and gender. J Am Acad Child Adolesc Psychiatry. 2011;50:554-62.

20. Shea CK, Lee MM, Lai KY, Luk ES, Leung PW. Prevalence of anxiety disorders in Hong Kong Chinese children with ADHD. J Atten Disord. 2018;22:403-13

21. Wajszilber D, Santiseban JA, Gruber R. Sleep disorders in patients with ADHD: impact and management challenges. Nat Sci Sleep. 2018;10:453-80.

22. Vila MT, Torres AM, Soto BB, Gomar MR, Langa MJ, Sierra Al. Relación entre el trastorno por déficit de atención e hiperactividad y los trastornos del sueño. Resultados de un estudio epidemiológico en la población escolar de la ciudad de Gandía. An Pediatr. 2008:69:251-7.

23. Pérez-Villena A, Soto-Insuga V, Castaño-De la Mota C, Martín-Del Valle F, Pons-Rodríguez M, Lozada-Del Pozo M. Importancia de los problemas de sueño en los niños con cefalea y otros trastornos del neurodesarrollo en las consultas de neuropediatría. Rev Neurol. 2016;62:61-7.

24. Hermann B, Jones J, Dabbs K, Allen CA, Sheth R, Fine J, et al. The frequency, complications and aetiology of ADHD in new onset paediatric epilepsy. Brain. 2007;130:3135-48.

25. Sand T, Breivik N, Herigstad A. Assessment of ADHD with EEG. Tidsskr Nor Laegeforen. 2013;133:312-6.

26. Cornelio-Nieto JO, Borbolla-Sala ME, Gallegos-Dimas A. Alteraciones electroencefalográficas en niños con trastorno por déficit de atención/ hiperactividad. Rev Neuro. 2011;52 Suppl 1:S97-101.

27. Mellon MW, Natchev BE, Katusic SK, Colligan RC, Weaver AL, Voigt RG, et al. Incidence of enuresis and encopresis among children with attention-deficit/hyperactivity disorder in a population-based birth cohort. Acad Pediatr. 2013;13:322-7

28. Yu B, Guo Q, Fan G, Ma H, Wang L, Liu N. Evaluation of working memory impairment in children with primary nocturnal enuresis: evidence from event-related functional magnetic resonance imaging. J Paediatr Child Health. 2011;47:429-35.

29. Lei D, Ma J, Du X, Shen G, Tian M, Li G. Altered brain activation during response inhibition in children with primary nocturnal enuresis: an fMRI study. Hum Brain Mapp. 2012;33:2913-9.

30. Ogrim G, Kropotov J, Hestad K. The quantitative EEG theta/beta ratio in attention deficit/hyperactivity disorder and normal controls: sensitivity, specificity, and behavioral correlates. Psychiatry Res. 2012;198:482-8.

31. Shreeram S, He JP, Kalaydjian A, Brothers S, Merikangas KR. Prevalence of enuresis and its association with attention-deficit/hyperactivity disorder among U.S. children: results from a nationally representative study. J Am Acad Child Adolesc Psychiatry. 2009;48:35-41.

32. Chou IC, Chang YT, Chin ZN, Muo CH, sung FC, Kuo HT, et al. Correlation between epilepsy and attention deficit hyperactivity disorder: a population-based cohort study. PLoS One. 2013;8:e57926.

33. Fonseca LC, Tedrus GM, Moraes Cd, Vicente Machado Ad, Almeida MP Oliveira DO. Epileptiform abnormalities and quantitative EEG in children with attention-deficit/hyperactivity disorder. Arq Neuropsiquiatr. 2008;66:462-7.

34. Joinson C, Heron J, Butler R, Von Gontard A, Butler U, Emond A, et al. A United Kingdom population-based study of intellectual capacities in children with and without soiling, daytime wetting, and bed-wetting. Pediatrics. 2007:120:e308-16.

35. Mikami AY, Normand S. The importance of social contextual factors in peer relationships in children with ADHD. Curr Dev Disord Rep. 2015;2:30-7.

36. Walcott CM, Landau S. The relation between disinhibition and emotion regulation in boys with attention deficit hyperactivity disorder. J Clin Child Adolesc Psychol. 2004;33:772-82.

37. Bioulac S, Micoulaud-Franchi JA, Philip P. Excessive daytime sleepiness in patients with ADHD-diagnostic and management strategies. Curr Psychiatry Rep. 2015;17:608.

38. Hvolby A. Associations of sleep disturbance with ADHD: implications for treatment. Atten Defic Hyperact Disord. 2015;7:1-8

39. Bechtel N, Kobel M, Penner IK, Specht K, Klarhöfer M, Scheffler K, et al. Attention-deficit/hyperactivity disorder in childhood epilepsy: a neuropsychological and functional imaging study. Epilepsia. 2012;53:325-33.

40. von Gontard A, Equit M. Comorbidity of ADHD and incontinence in children. Eur Child Adolesc Psychiatry. 2015;24:127-40. 